\title{
Perianal herpetic ulcers in immunosuppressed patients. Report of two cases
}

\section{María Lorena Re Domínguez, Evelín Magalí Cuevas Jara, Guadalupe Barboza, Beatriz Di Martino Ortiz, Mirtha Rodríguez Masi, Oilda Knopfelmacher Domínguez, Lourdes Bolla de Lezcano}

Department of Dermatology, Clinicas Hospital, Faculty of Medical Sciences, National University of Asuncion, Paraguay

Corresponding author: Prof. Beatriz Di Martino Ortiz, E-mail: beatrizdimartino@gmail.com

\begin{abstract}
Genital herpes is the most common cause of ulcers in sexually transmitted diseases (STDs). It is presented as a single or multiple, painful injury, accompanied by bilateral, also painful, lymphadenopathy. In immunocompromised patients, such as those affected by HIV, Herpes Simplex Virus (HSV) infections have a variety of clinical manifestations; they may be located, scattered or atypical. In addition, lesions may be more extensive and persistent than HIV-negative patients. We present two cases of immunocompromised patients with perianal herpetic ulcers, one HIV carrier, and the other with leukopenia caused by visceral Leishmaniasis.
\end{abstract}

Key words: Perianal herpes; Immune deficiency; Ulcers

\footnotetext{
How to cite this article: Re Domínguez ML, Cuevas Jara EM, Barboza G, Di Martino Ortiz B, Rodríguez Masi M, Knopfelmacher Domínguez O, Bolla de Lezcano L. Perianal herpetic ulcers in immunosuppressed patients. Report of two cases. Our Dermatol Online. 2017;8(2):189-194.

Submission: 20.08.2016; Acceptance: 24.10.2016

DOI: 10.7241 /ourd.20172.51
} 


\title{
Ulceras herpéticas perianales en pacientes inmunodeprimidos. Presentación de dos casos
}

\section{María Lorena Re Domínguez, Evelín Magalí Cuevas Jara, Guadalupe Barboza, Beatriz Di Martino Ortiz, Mirtha Rodríguez Masi, Oilda Knopfelmacher Domínguez, Lourdes Bolla de Lezcano}

Department of Dermatology, Clinicas Hospital, Faculty of Medical Sciences, National University of Asuncion, Paraguay

Corresponding author: Dra. Beatriz Di Martino Ortiz, E-mail: beatrizdimartino@gmail.com

\begin{abstract}
RESUMEN
El herpes genital es la causa más frecuente de úlceras dentro de las enfermedades de transmisión sexual (ETS). Se presenta como una lesión única o múltiple, dolorosa, acompañada de adenopatías bilaterales también dolorosas. En pacientes inmunodeprimidos, como por ejemplo en los afectados por el VIH, las infecciones por el Virus del Herpes Simple (VHS) presentan una gran variedad de manifestaciones clínicas pudiendo éstas, ser localizadas, diseminadas o atípicas. Además, las lesiones pueden ser más extensas y persistentes que en VIH negativos. Presentamos dos casos de pacientes inmunodeprimidos con úlceras herpéticas perianales, uno portador del VIH, y otro con leucopenia por Leishmaniasis visceral.
\end{abstract}

Palabras claves: Herpes perianal; Inmunodepresión; Úlceras

\section{INTRODUCCIÓN}

El Herpes genital es provocado por un virus ADN, VHS tipos 1 y 2; puede cursar de manera crónica con recidivas hasta en un $40 \%$ de los pacientes. El tipo de herpes implicado en el $90 \%$ de estos casos, es el tipo 2 , y sólo un $10 \%$ el tipo 1 , en muy raras ocasiones puede encontrarse el virus de la varicela zoster [1].

La gravedad de la infección por herpes aumenta en presencia de inmunosupresión. Ulceraciones necróticas pueden aparecer en sitios inusuales y pueden producirse lesiones más extensas y crónicas en los pacientes inmunosuprimidos. Las lesiones asintomáticas perianales ocasionadas por VHS se observan con mayor frecuencia en individuos seropositivos al VIH [2].

Rodríguez y col., refieren que el 64\% de los pacientes que tienen úlceras anales inespecíficas presentan el virus del herpes simple; y que en el 6 al 30\% de los hombres que tienen sexo con hombres (HSH), que padecen patología anal, coexiste el virus del herpes simple [1].

La transmisión del Herpes genital y perianal, es por implantación directa, es altamente contagioso y los síntomas aparecen de 4 a 21 días posteriores a la inoculación. Entre las lesiones más frecuentes se encuentran eritema y vesículas, las cuales se acompañan de dolor perianal, sensación urente, prurito en un 50 a 85\% de los casos, linfadenopatía inguinal, e inclusive rectorragia. La radiculopatía puede encontrarse en un $50 \%$ y los signos neurológicos pueden persistir posterior a la infección aguda [1].

Las lesiones herpéticas ulceradas ayudan a la transmisión sexual del VIH. Las manifestaciones atípicas de herpes tales como úlceras hemorrágicas profundas dolorosas, placa verrugosa con ulceración, placas verrugosas hiperqueratósicas, eritema multiforme, erupción eritematosa generalizada y exantema pápulo vesiculoso, se presentan en las personas afectadas por el VIH. La localización más frecuente de ulceración

\footnotetext{
How to cite this article: Re Domínguez ML, Cuevas Jara EM, Barboza G, Di Martino Ortiz B, Rodríguez Masi M, Knopfelmacher Domínguez O, Bolla de Lezcano L. Ulceras herpéticas perianales en pacientes inmunodeprimidos. Presentación de dos casos. Our Dermatol Online. 2017;8(2):189-194. 
es la región perianal. La diseminación viral subclínica es significativamente más común en pacientes con VIH [2].

El diagnóstico es clínico, y en los casos dudosos y atípicos, se apoya en el test de Tzanck, la histopatología, la inmunofluorescencia y el cultivo de las lesiones vesiculares.

El tratamiento es con antivirales tales como el Aciclovir, el Valaciclovir y el Fanciclovir [1].

\section{CASOS CLÍNICOS}

\section{Caso 1}

Mujer, 41 años, soltera, procedente de medio urbano del Paraguay, con diagnóstico de SIDA estadio C3, con recuento de linfocitos CD4 de 106 cél $/ \mathrm{mm}^{3}$, toxoplasmosis cerebral, candidiasis oral, diarrea crónica, en tratamiento con Zidovudina, Lamivudina, Efavirenz, Sulfadiazina, Pirimetadina y Fluconazol, con cuadro de 1 mes de evolución de granos rojos en región perianal, dolorosos, que luego presentan contenido líquido. Aumentan de tamaño y se ulceran. Examen físico: Placas eritematosas con halo hiperpigmentado y centro ulcerado, bordes irregulares, límites netos, fondo fibrinoso, de $2-4 \mathrm{~cm}$ de diámetro en región interglútea y tercio superointerno de muslo izquierdo (Fig. 1).

\section{Caso 2}

Varón, 59 años, casado, procedente de medio urbano del Paraguay, con lesiones a repetición en piel de la región perianal, de 2 años de evolución, que se inician como granos rojos no dolorosas, que aumentan de tamaño, secretan líquido transparente y curan espontáneamente, reapareciendo luego de 6 a 8 semanas. El cuadro actual es de 2 semanas de evolución. Al momento de la evaluación dermatológica, el paciente se encontraba internado, con diagnóstico de Leishmaniosis Visceral en tratamiento con Antimoniato de Meglumina en su día 19. Examen físico: Ulceras de 1 a $2 \mathrm{~cm}$ de diámetro de bordes regulares y límites netos, fondo granulomatoso, rodeadas de halo hiperpigmentado de aprox $3 \mathrm{~cm}$ de diámetro que asientan en región perianal y línea interglútea (Fig. 2). Laboratorio: anemia moderada, plaquetopenia y leucopenia de 1.200 células $/ \mathrm{mm}^{3}$. VDRL y ELISA para HIV no reactivos.

\section{Histopatología}

Ambos casos compartían los mismos hallazgos histopatológicos consistentes en ulceración epidérmica y presencia de células acantolíticas eosinofílicas, balonizadas y células multinucleadas con núcleos en vidrio esmerilado (cromatina periférica y claridad central). Infiltrado de neutrófilos en dermis (Fig. 3).

\section{Diagnóstico Final}

en ambos casos Úlcera por Herpes Virus.

\section{Tratamiento}

Aciclovir vía oral 800 mg tres veces al día por 10 días

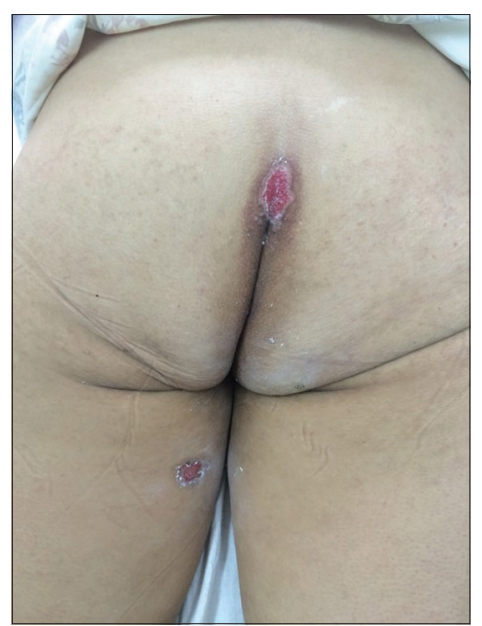

Figura 1: Clínica. Caso 1. Placas eritematosas de 2-4 cm de diámetro con halo hiperpigmentado y centro ulcerado, bordes irregulares, límites netos, fondo fibrinoso, en región interglútea y tercio superointerno de muslo izquierdo.

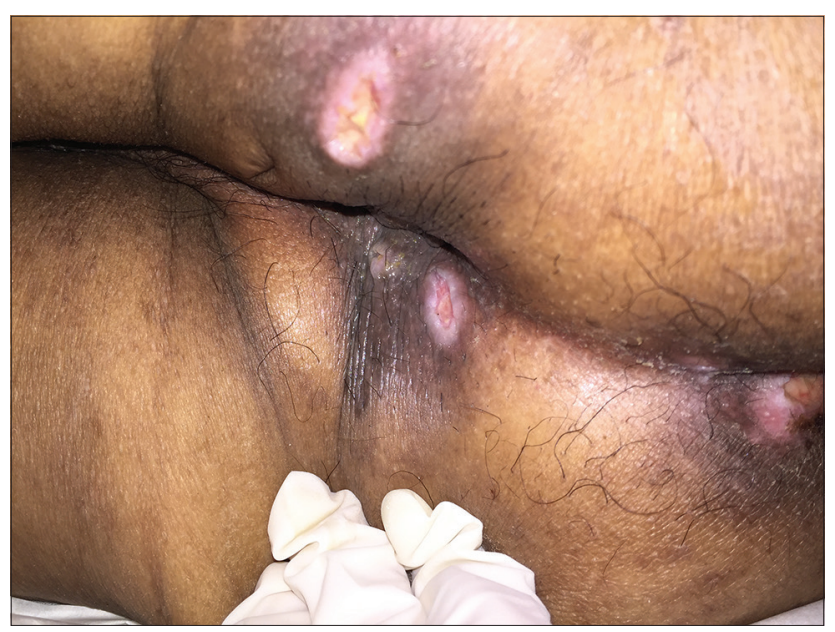

Figura 2: Clínica. Caso 2. Ulceras de 1 a $2 \mathrm{~cm}$ de diámetro de bordes regulares y límites netos, fondo granulomatoso, rodeadas de halo hiperpigmentado de $3 \mathrm{~cm}$ de diámetro que asientan en región perianal y línea interglutea. 


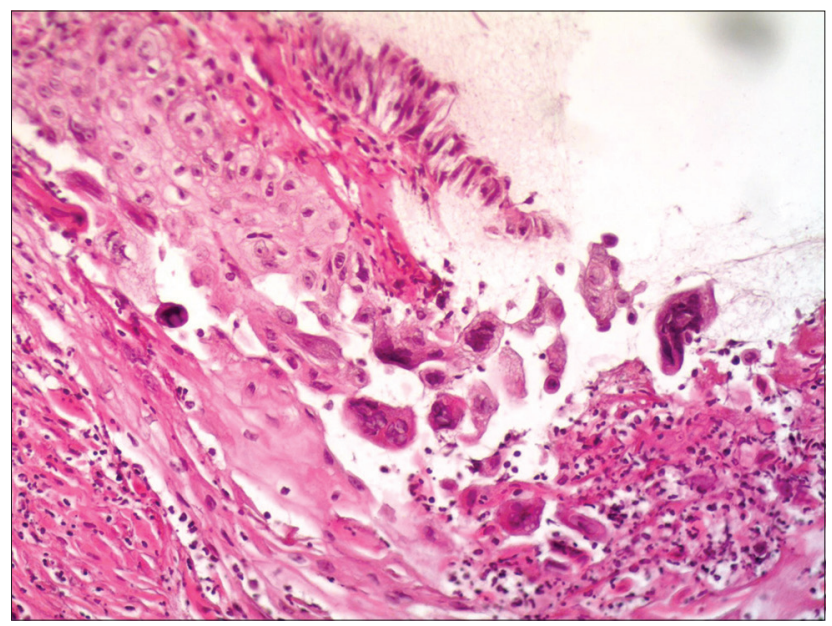

Figura 3: Histopatología. Células acantolíticas eosinofílicas, balonizadas y células multinucleadas con núcleos en vidrio esmerilado (cromatina periférica y claridad central). Infiltrado de neutrófilos en dermis (HE 40X).

en el caso 1 y por 7 días en el caso 2. Curaciones de la úlcera con suero fisiológico y aplicación de crema de Lidocaina y Sulfadiazina de Plata. Ambos casos presentaron buena evolución.

\section{DISCUSIÓN}

El herpes genital es la ETS más común en los individuos seropositivos al VIH [2]; además de ser la causa de lesión ulcerada genital más frecuente dentro de las ETS en la población general [3].

Existe reactivación subclínica de VHS en pacientes con infección por $\mathrm{VIH}$; menos de $10 \%$ de las reactivaciones presentan síntomas [4]. Se refiere que la infección aguda y las recurrencias por VHS, principalmente el tipo 2, pueden estimular la replicación del VIH $[5,6]$, y se asocian a un aumento de dos a cuatro veces del riesgo de transmisión del VIH. Ambos virus se encuentran involucrados en un círculo vicioso, en donde el VIH-1 facilita la adquisición y reactivación del herpes virus, y éste facilita la adquisición y replicación del VIH $[5,7]$.

Los VHS se transmiten a través del contacto de las membranas mucosas, asociándose comúnmente a enfermedad labial en el tipo 1 y anogenital en el tipo 2 , aunque el número de casos de infección cruzada ha ido en aumento, secundario a la exposición sexual orogenital. En el paciente inmunocompetente las lesiones cutáneas se presentan en genitales externos, región perianal, cavidad oral y labios; son localizadas y están conformadas por lesiones que inician como vesículas pequeñas, dolorosas, agrupadas, con base eritematosa, que posteriormente se ulceran y resuelven en dos semanas sin tratamiento $[5,8]$.

En los pacientes con deterioro en su sistema inmunológico, tal como son nuestros casos, las lesiones herpéticas ocurren con mayor frecuencia, son atípicas y poseen menor probabilidad de autolimitarse en comparación con las lesiones presentadas en pacientes inmunocompetentes [8]. En nuestro caso del paciente HIV negativo, con úlceras herpéticas perianales, el factor de inmunosupresión estaba dado por la leucopenia secundaria a la Leishmaniasis visceral, lo que nos demuestra que cualquier paciente inmunodeprimido es susceptible de padecer este tipo de lesiones y no sólo los casos vinculados al VIH.

El diagnóstico se realiza mediante la histopatología, en donde se observan las células gigantes multinucleadas características. Existen otros métodos diagnósticos directos, entre los que se encuentran el aislamiento viral mediante cultivo (método de elección para distinguir entre herpes virus tipo 1 o 2), la detección del antígeno viral mediante inmunofluorescencia directa, la microscopía electrónica (no distingue el tipo de herpes) y la detección del ADN viral mediante técnicas de hibridación [5,9].

Entre los diagnósticos diferenciales de las úlceras perianales se encuentran patologías infecciosas, inflamatorias y neoplásicas [1,2,10-13]. Los principales diagnósticos diferenciales de Úlceras Perianales se muestran en la Tabla 1.

El tratamiento del virus del herpes simple tipo 1 y 2 es combinado, local y sistémico. Se recomienda el uso de secantes tópicos y antisépticos locales, como el sulfato de cobre, para prevenir diseminación y sobreinfecciones [5].

Los antivirales recomendados son: Aciclovir VO 400 a 800 mg/8 Hs durante 7 a 10 días; Valaciclovir VO 1 g/12 Hs en casos de infecciones recurrentes, y Famciclovir VO 500 mg/12 Hs durante 7-10 días [14].

En el caso de pacientes inmunosuprimidos con enfermedad severa, complicaciones o afectación del sistema nervioso central se recomienda: Aciclovir IV, 5 a $10 \mathrm{mg} / \mathrm{kg} / 8 \mathrm{Hs}$ durante 2 a 7 días hasta que se observe mejoría clínica, seguido de Aciclovir VO al hasta completar 10 días de tratamiento $[5,10,14]$.

La respuesta a Aciclovir es excelente, salvo en algunos pacientes con muy bajo recuento de CD4 $(<50$ 
www.odermatol.com

Tabla 1: Diagnósticos diferenciales de úlceras perianales

\begin{tabular}{|c|c|c|c|c|}
\hline Entidad & Etiología & Clínica & Histopatología & Diagnóstico \\
\hline Herpes virus & $\begin{array}{l}\text { Herpes simple } \\
\text { virus tipo } 1 \text { y } 2\end{array}$ & $\begin{array}{l}\text { Eritema y vesículas Úlceras } \\
\text { necróticas y hemorrágicas } \\
\text { dolorosas Placa verrugosa con } \\
\text { ulceración Placa verrugosa } \\
\text { hiperqueratósica }\end{array}$ & $\begin{array}{l}\text { Células balonizadas y acantolíticas } \\
\text { Células multinucleadas con núcleos en } \\
\text { vidrio esmerilado }\end{array}$ & $\begin{array}{l}\text { Clínica } \\
\text { Test de tzanck, histopatología, IFI } \\
\text { Cultivo de las vesículas } \\
\text { PCR }\end{array}$ \\
\hline Citomegalovirus & Citomegalovirus & $\begin{array}{l}\text { Pápulas, vesículas, ampollas y } \\
\text { úlceras mucocutáneas }\end{array}$ & $\begin{array}{l}\text { Células grandes con inclusiones } \\
\text { intracitoplasmáticas o intranucleares } \\
\text { basofílicas (owls eyes), que afectan } \\
\text { células endoteliales o periendoteliales }\end{array}$ & $\begin{array}{l}\text { Clínica, histopatología, PCR, } \\
\text { cultivo }\end{array}$ \\
\hline Micobacteriosis & $\begin{array}{l}\text { Mycobacterium } \\
\text { avium } \\
\text { intracellulare }\end{array}$ & $\begin{array}{l}\text { Placas verrugosas } \\
\text { Úlceras } \\
\text { Fístulas }\end{array}$ & $\begin{array}{l}\text { Granulomas supurativos. Variable } \\
\text { presencia de BAAR }\end{array}$ & $\begin{array}{l}\text { Clínica, } \\
\text { Histopatología con tinción Ziehl } \\
\text { Neelsen } \\
\text { PCR } \\
\text { Cultivo }\end{array}$ \\
\hline $\begin{array}{l}\text { Tuberculosis } \\
\text { orificial }\end{array}$ & $\begin{array}{l}\text { Mycobacterium } \\
\text { tuberculosis }\end{array}$ & Úlceras dolorosas & $\begin{array}{l}\text { Granulomas caseificantes y numerosos } \\
\text { BAAR }\end{array}$ & $\begin{array}{l}\text { Clínica } \\
\text { Histopatología con tinción Ziehl } \\
\text { Neelsen } \\
\text { Frotis para BAAR de orina y } \\
\text { expectoración } \\
\text { PCR }\end{array}$ \\
\hline Sífilis & $\begin{array}{l}\text { Treponema } \\
\text { pallidum }\end{array}$ & $\begin{array}{l}\text { Chancro } \\
\text { Pápula } \\
\text { Úlcera }\end{array}$ & $\begin{array}{l}\text { Inespecífico: Infiltrado linfohistiocitario } \\
\text { con abundantes células plasmáticas } \\
\text { perivasculares }\end{array}$ & $\begin{array}{l}\text { Clínica } \\
\text { Microscopía de campo oscuro } \\
\text { Pruebas no treponémicas: VDRL } \\
\text { o RPR } \\
\text { Pruebas treponémicas: FTA-abs, } \\
\text { MHS-TP, TPPA }\end{array}$ \\
\hline $\begin{array}{l}\text { Chancroide o } \\
\text { chancro blando }\end{array}$ & $\begin{array}{l}\text { Haemophilus } \\
\text { ducrey }\end{array}$ & $\begin{array}{l}\text { Dolor, úlceras, abscesos con } \\
\text { supuración y ganglios regionales }\end{array}$ & $\begin{array}{l}\text { Inespecífico. Presenta tres zonas: una } \\
\text { necrótica superficial, una media de } \\
\text { neo vascularización, y otra profunda } \\
\text { con infiltrado linfocitario y de células } \\
\text { plasmáticas }\end{array}$ & $\begin{array}{l}\text { Clínica y } \\
\text { Cultivo para gram negativos y } \\
\text { aerobios }\end{array}$ \\
\hline Clamidia & $\begin{array}{l}\text { Chlamydia } \\
\text { trachomatis }\end{array}$ & Úlceras, dolor, tenesmo & $\begin{array}{l}\text { Abscesos crípticos, granulomas y } \\
\text { células gigantes }\end{array}$ & Clínica, cultivo e histopatología \\
\hline Amebiasis & $\begin{array}{l}\text { Entamoeba } \\
\text { histolytica }\end{array}$ & $\begin{array}{l}\text { Eritema, edema y úlceras } \\
\text { perianales }\end{array}$ & $\begin{array}{l}\text { Ulceración epidérmica y presencia de } \\
\text { trofozoitos de Entamoeba histolytica }\end{array}$ & $\begin{array}{l}\text { Clínica y coproparasitológico } \\
\text { donde se observan quistes de } \\
\text { Entamoeba histolytica }\end{array}$ \\
\hline $\begin{array}{l}\text { Enfermedad de } \\
\text { crohn }\end{array}$ & Inflamatoria & $\begin{array}{l}\text { Fisura, fístula absceso } \\
\text { Úlcera con repliegue epitelial } \\
\text { semejante a "la oreja de elefante" }\end{array}$ & $\begin{array}{l}\text { Infiltrado granulomatoso constituido por } \\
\text { células epitelioides y células gigantes } \\
\text { de tipo Langhans, sin caseificación } \\
\text { central, rodeado de linfocitos y } \\
\text { plasmocitos }\end{array}$ & $\begin{array}{l}\text { Clínica } \\
\text { Histopatología y } \\
\text { Endoscopía }\end{array}$ \\
\hline $\begin{array}{l}\text { Pioderma } \\
\text { gangrenoso }\end{array}$ & $\begin{array}{l}\text { Inflamatoria } \\
\text { Dermatosis } \\
\text { neutrofílica }\end{array}$ & Úlceras necrotizantes & $\begin{array}{l}\text { Variable según la etapa evolutiva } \\
\text { Granulomas supurativos, histiocitos, } \\
\text { macrófagos, células multinucleadas } \\
\text { Edema dérmico papilar, espongiosis, } \\
\text { abscesos neutrofílicos epidérmicos }\end{array}$ & $\begin{array}{l}\text { Correlación de hallazgos clínicos e } \\
\text { histopatológicos } \\
\text { Exclusión de otras entidades }\end{array}$ \\
\hline $\begin{array}{l}\text { Carcninoma } \\
\text { espínocelular } \\
\text { in situ (Enfermedad } \\
\text { de bowen) }\end{array}$ & $\begin{array}{l}\text { Neoplasia. } \\
\text { Se ha visto } \\
\text { asociado } \\
\text { con virus del } \\
\text { papiloma } \\
\text { humano } 16 \text { y } 18\end{array}$ & $\begin{array}{l}\text { Prurito, ardor, hiperpigmentación, } \\
\text { ulceración }\end{array}$ & $\begin{array}{l}\text { Pérdida de la polaridad epidérmica, } \\
\text { afectación de todo el espesor } \\
\text { epidérmico por queratinocitos atípicos, } \\
\text { pleomórficos e hipercromáticos. } \\
\text { Lámina Basal intacta }\end{array}$ & Clínico e histopatológico \\
\hline Linfoma cutáneo T & Neoplasia & Fístulas, abscesos y úlceras & $\begin{array}{l}\text { Proliferación celular de células } \\
\text { linfoides, epidermotropismo, linfocitos } \\
\text { cerebriformes, mitosis, índice de } \\
\text { proliferación elevado }\end{array}$ & $\begin{array}{l}\text { Clínica, histopatología, } \\
\text { inmunohistoquímica }\end{array}$ \\
\hline
\end{tabular}

IFI: Inmunofluorescencia Indirecta, PCR: Reacción en Cadena de la Polimerasa, BAAR: Bacilos ácido-alcohol resistente, VDRL: Venereal Disease Research Laboratory, RPR: Rapid Plasma Reagin, FTA-abs: absorción de anticuerpos fluorescentes treponémicos, MHA-TP: Microhemaglutinación de anticuerpos contra Treponema pallidum, TPPA: ensayo de aglutinación de partículas del T. pallidum, Re M.L., Cuevas M., Barboza G., Di Martino B, Rodríguez M., Knopfelmacher O., Bolla L. Cátedra de Dermatología. Hospital de Clínicas. Facultad de Ciencias Médicas. Universidad Nacional de Asunción-Paraguay.

células $\left./ \mathrm{mm}^{3}\right)$; en tales casos, la tasa de recurrencia es muy alta y se requiere tratamiento con dosis más altas y por períodos más largos [1].
En nuestros pacientes, hemos obtenido excelente respuesta con Aciclovir $\mathrm{VO}$ a razón de $800 \mathrm{mg} / 8$ horas por 10 y 7 días respectivamente. 
El tratamiento se complica frecuentemente por la resistencia a los antivirales dependientes de la timidina quinasa (TK), incluyendo Aciclovir, Valaciclovir y Famciclovir. El cultivo del virus sigue siendo una herramienta esencial para las pruebas de sensibilidad a los medicamentos antivirales. Las alternativas terapéuticas incluyen antivirales no TK-dependientes, tales como el Foscarnet o Cidofovir, que se dirigen directamente a la polimerasa del ADN viral [4].

\section{CONCLUSION}

Las úlceras perianales, sobre todo en los pacientes inmunocomprometidos son de origen muy variado. El Herpes genital es la lesión ulcerada más frecuente dentro de las Enfermedades de Transmisión Sexual. El diagnóstico se basa en la clínica, serología y la biopsia con el estudio anatomopatológico.

\section{BIBLIOGRAFÍA}

1. Rodríguez M, Neri Carmona M, Jalife A, Alarcón H. Patologías más frecuentes del área perianal. Perianal more frequent diseases. Rev Cent Dermatol Pascua. 2000;9:86-95.

2. Kumar L, Shanmugasekar C, Lakshmi C, Srinivas C. Herpes misdiagnosed as pyoderma gangrenosum. Indian J Sex Transm Dis. 2009;30:106-8.

3. Misa Jalda R. Manifestaciones anorrectales de las enfermedades de transmisión sexual. Anorectal manifestations of sexually trasmitted infections. Rev Mex Coloproctol. 2009;15:39-45.

4. Wauters O, Lebas E, Nikkels AF. Chronic mucocutaneous herpes simplex virus and varicella zoster virus infections. J Am Acad
Dermatol. 2012;66:e217-27.

5. Garza-Garza R, González-González S, Ocampo-Candiani J. Manifestaciones cutáneas del VIH. Cutaneous manifestations of HIV. Gaceta Méd Méx. 2014;150:194-221.

6. Sartori E, Calistri A, Salata C, Del Vecchio C, Palù G, Parolin C. Herpes simplex virus type 2 infection increases human immunodeficiency virus type 1 entry to human primary macrophages. Virol J. 2011;12:166.

7. Van de Perre P, Segondy M, Foulongne V, Ouedraogo A, Konate I, Huraux JM, el al. Herpes simplex virus and HIV-1: deciphering viral synergy. Lancet Infect Dis. 2008;8:490-7.

8. Severson JL, Tyring SK. Relation between herpes simplex viruses and human immunodeficiency infections. Arch Dermatol. 1999;135:1393-7.

9. Singh A, Preiksaitis J, Ferencz A, Romanowski B. The laboratory diagnosis of herpes simplex virus infections. Can J Infect Dis Med Microbiol. 2005;16:92-8.

10. Alvite M, Monjero I, Alonso L, Álvarez A, González R, Maseda R, et al. Pioderma Gangrenoso Con Extensa Afectación Perianal. Pyoderma gangrenosum with extensive perianal involvement. Rev Esp Enferm Dig. 2012;104:92-3.

11. lvanov M, Verea A, Bourimborde M. Chancro blando. Presentación de dos casos y revisión de la literatura. Chancroid. Report of two cases and review of the literatura. Arch Argent Dermatol. 2007;57:103-12.

12. Tincopa O, Sánchez L. Tuberculosis Cutánea. Cutaneous tuberculosis. Dermatol Peru. 2003;13:195-217.

13. Abbiati A, Bertolotti M, Orsini P, Martín C, Verea M. Enfermedad de Crohn perianal: a propósito de un caso. Perianal Crohn`s disease: case report. Arch Argent Dermatol. 2015;65:167-70.

14. Genital HSV Infections - 2015 STD Treatment Guidelines. Centers for Disease Control and Prevention. Año 2015. Disponible en: http://www.cdc.gov/std/tg2015/herpes.htm

Copyright by María Lorena Re Domínguez, et al. This is an open-access article distributed under the terms of the Creative Commons Attribution License, which permits unrestricted use, distribution, and reproduction in any medium, provided the original author and source are credited. Source of Support: Nil, Conflict of Interest: None declared. 